\title{
Matriz porosa do BV60S no tratamento de defeitos ósseos críticos em rádios de cães
}

\author{
[Porous matrix of BG60S in the treatment of critical bone \\ defects in the radius of dogs] \\ E.G.L. Alves ${ }^{1,2}$, R. Serakides ${ }^{2}$, I.R. Rosado ${ }^{1,2}$, J.A.C. Varon $^{2}$, O.L.A. Paez ${ }^{3}$, F.N. Machado ${ }^{3}$, \\ F.B. Fukushima ${ }^{3}$, M.M. Pereira ${ }^{3}$, C.M.F. Rezende ${ }^{2}$ \\ ${ }^{1}$ Universidade de Uberaba - Uberaba, MG \\ ${ }^{2}$ Escola de Veterinária - Universidade Federal de Minas Gerais - Belo Horizonte, MG \\ ${ }^{3}$ Escola de Engenharia - Universidade Federal de Minas Gerais - Belo Horizonte, MG
}

\section{RESUMO}

O objetivo deste estudo foi avaliar o efeito da matriz porosa do biovidro de composição molar $60 \% \mathrm{SiO} 2$ - 36\% CaO - 4\% P2O5 (BV60S) no tratamento de defeitos ósseos críticos de cães. Foram utilizados 20 cães, machos, sem raça definida, com dois anos e massa corporal média de $25 \mathrm{~kg}$. Foram constituídos três grupos experimentais: defeitos ósseos preenchidos com BV60S (BV), com osso autógeno (C+) e defeitos não preenchidos (C-). A regeneração óssea foi avaliada por meio de exames radiográficos, densitométricos e histomorfométricos ao longo de 90 dias. A matriz do BV60S mostrou rápida reabsorção com redução média de $12,62 \%$ a cada 15 dias. A regeneração foi completa no grupo $\mathrm{C}+\mathrm{e}$ incompleta nos grupos BV e C-, aos 90 dias. A área de neoformação óssea foi semelhante entre os grupos BV e C-, em todos os tempos estudados. Conclui-se que a matriz porosa do BV60S possui rápida reabsorção, não sendo eficiente no tratamento de defeitos ósseos críticos em rádios de cães.

Palavras-chave: cão, regeneração óssea, ortopedia, biomateriais

\begin{abstract}
The aim of this study was to evaluate the effect of the porous matrix of bioglass with molar composition of $60 \% \mathrm{SiO}, 36 \% \mathrm{CaO}, 4 \% \mathrm{P} 2 \mathrm{O} 5$ (BV60S) in the treatment of critical bone defects in dogs. 20 male mongrel dogs at two years of age and a mean weight of $25 \mathrm{~kg}$ were used. Three experimental groups were formed: bone defects filled with BV6OS (BV), with autogenous bone $(C+)$ and unfilled defects $(C-)$. Bone regeneration was evaluated by radiography, bone densitometry and histoforfometry over 90 days. The matrix of BV60S showed rapid absorption with an average reduction of $12.62 \%$ every 15 days. Regeneration was complete in group $C+$ and incomplete in the $B V$-group and $C$-group at 90 days. The area of new bone formation was similar between $B V$ and $C$ - groups at all time points. It was concluded that the porous matrix BV60S has fast resorption not being effective in the treatment of critical bone defects in the radius of dogs.
\end{abstract}

Keywords: dog, bone regeneration, orthopedics, biomaterials

\section{INTRODUÇÃO}

O tratamento de defeitos ósseos críticos ainda é um dos maiores desafios da ortopedia veterinária e humana. São considerados críticos aqueles defeitos incapazes de se regenerarem naturalmente sem algum tipo de tratamento adicional à fixação (ASTM 2010). Até o presente momento, o enxerto autógeno é considerado a melhor alternativa para o tratamento de defeitos ósseos críticos, mas alguns inconvenientes, como

Recebido em 9 de junho de 2014

Aceito em 3 de março de 2015

E-mail: endrigogabellini@yahoo.com.br 
maior tempo cirúrgico, complicações no local da colheita, fragilização do local e a quantidade limitada de osso coletado estão associados a esse tipo de enxertia (Piermattei et al., 2006). Devido a isso, muito se tem estudado em busca de alternativas eficientes para a substituição dessa forma de enxertia, e a produção de matrizes sintéticas a partir de biomateriais parece ser a alternativa mais viável e promissora (Pereira $e t$ al., 2006; Rahaman et al., 2011). Diferentes tipos de biomaterias podem ser utilizados para a produção dessas matrizes sintéticas, mas o grupo das biocerâmicas se destaca, uma vez que favorece a regeneração óssea por osteocondução (Dutra et al., 2008) e, em alguns casos, por osteoindução (Hoppe et al., 2011). Dentre as biocerâmicas, os vidros são considerados os mais ativos e favoráveis à regeneração óssea. Quando implantados no osso, reagem com o fluido intersticial, desencadeando uma cascata de reações físico-químicas e eventos celulares que culminam com a formação de uma camada de hidroxiapatita biológica, deposição e mineralização de osteoide em sua superfície, o que favorece sua ligação ao osso e promove uma interface coesa e resistente (Hench, 2009). O efeito do biovidro na regeneração óssea pode variar de acordo com a composição química, grau de organização das moléculas, topografia e microestrutura da matriz, bem como com as condições do microambiente de implantação, que podem determinar maior ou menor dissolução do biomaterial e consequentemente alterar seu efeito biológico (Rahaman et al., 2011). O biovidro 60S (BV60S) de composição molar $4 \% \quad \mathrm{P}_{2} \mathrm{O}_{5}$; $36 \% \mathrm{CaO} ; 60 \% \mathrm{SiO}_{2}$ é um desses biomateriais e pode ser produzido de forma porosa com uma arquitetura que mimetiza o osso esponjoso. $\mathrm{O}$ BV60S já mostrou efeitos benéficos na regeneração óssea in vitro, favorecendo a proliferação de osteoblastos de ratos (Valerio et al., 2004) e aumentando a osteogênese durante o processo de diferenciação osteogênica de CTMAD de cães (Alves, 2013; Alves et al., 2015). In vivo, o BV60S permitiu a regeneração de defeitos ósseos não críticos em mandíbulas de cães (Dutra et al., 2008), mas ainda não foi testado em defeitos ósseos críticos, que são considerados o maior problema do ponto de vista clínico. Dessa forma, o objetivo do presente estudo foi avaliar a matriz porosa do BV60S no tratamento de defeitos ósseos críticos em rádios de cães. 


\section{MATERIAL E MÉTODOS}

Este estudo foi realizado de acordo com as normas internacionais de bem-estar animal após aprovação pelo Comitê de Ética em Experimentação Animal da UFMG (protocolo $n^{\circ}$ 157/2009).

Para produção da matriz porosa do BV60S, foram adicionados, em um béquer, $133,8 \mathrm{~mL}$ de tetraetilortosilicato (TEOS) e $13,6 \mathrm{~mL}$ de trietilfosfato (TEP), e, em outro, $97,9 \mathrm{~mL}$ de água deionizada e $16,3 \mathrm{~mL}$ de solução de ácido nítrico $2 \mathrm{~N}$; as soluções foram homogeneizadas e reservadas. Em seguida as duas soluções foram misturadas em um terceiro béquer maior e mantidas sob agitação magnética por 60 minutos com o objetivo de hidrolisar o TEOS. Transcorrido esse período, 85,01g de nitrato de cálcio $\left[\mathrm{Ca}\left(\mathrm{NO}_{3}\right)_{2} \quad 4 \mathrm{H}_{2} \mathrm{O}\right]$ foi gradativamente adicionado à solução que permaneceu sob agitação magnética por mais 30 minutos. Para permitir aeração e formação da espuma do biovidro $60 \mathrm{~S}$, foi adicionado $1 \mathrm{~mL}$ de surfactante para cada $80 \mathrm{~mL}$ de solução. Em seguida $4 \mathrm{~mL}$ de solução aquosa de ácido fluorídrico (HF) $10 \%$ A porosidade total da matriz do biovidro $60 \mathrm{~S}$ foi calculada pela seguinte fórmula:

Porosidade total $(\%)=\left(\frac{\text { densidade verdadeira }- \text { densidade volumétrica }}{\text { densidade verdadeira }}\right) \times 100$,

em que a densidade verdadeira foi medida por picnometria de Hélio $\left(2,7 \mathrm{~g} / \mathrm{cm}^{3}\right)$ e a densidade volumétrica foi calculada dividindo-se a massa da matriz $(\mathrm{g})$ pelo seu volume $\left(\mathrm{cm}^{3}\right)$.

Para análise morfológica da estrutura porosa, as matrizes foram recobertas com carbono (SPI/Supplies-EUA) e analisadas por microscopia eletrônica de varredura (MEV-FEIInspect-S50/República Tcheca).

Para criação dos defeitos ósseos críticos e tratamento com matriz porosa do BV60, utilizaram-se 20 cães hígidos, machos, sem raça definida, com dois anos de idade e massa corporal média de $25 \mathrm{~kg}$. Os cães foram aleatoriamente distribuídos em dois grupos experimentais: grupo controle negativo (C-) animais com defeitos ósseos críticos sem preenchimento $(\mathrm{n}=10)$ e grupo tratado com BV60S (BV) - animais com defeitos ósseos críticos tratados com matriz porosa do BV60S $(n=10)$. O controle positivo $(C+)$ foi realizado em todos os animais utilizando-se o rádio foi acrescida a $100 \mathrm{~mL}$ da solução final para catalisar a sua gelificação. A solução foi então aerada por dois minutos com o auxílio de uma batedeira elétrica, e após esse período a espuma de biovidro foi vertida em um recipiente de polipropileno cujo interior possuía forma cilíndrica com $2 \mathrm{~cm}$ de diâmetro e $3 \mathrm{~cm}$ de altura. $\mathrm{O}$ recipiente foi então hermeticamente fechado e incubado a $60^{\circ} \mathrm{C}$ em estufa por 72 horas para gelação e maturação. Transcorrido esse período, a tampa do recipiente foi trocada por outra com múltiplos orifícios, e o biovidro foi submetido a um protocolo de secagem em estufa, permanecendo a $60^{\circ} \mathrm{C}$ por 72 horas, seguindo-se um aumento gradual da temperatura em $10^{\circ} \mathrm{C}$ a cada 24 horas, até atingir a temperatura de $120^{\circ} \mathrm{C}$. Após a secagem as amostras do biovidro $60 \mathrm{~S}$ foram tratadas termicamente na mufla a $700^{\circ} \mathrm{C}$, por 6 horas, quando foi utilizada uma taxa de aquecimento e de resfriamento de $1{ }^{\circ} \mathrm{C}$ por minuto (Coelho et al., 2005). Após o tratamento térmico, as amostras foram embaladas separadamente em recipientes plásticos hermeticamente fechados e esterilizadas por radiação gama. contralateral, com defeito crítico preenchido com o próprio fragmento ósseo retirado da ostectomia.

Para realização das cirurgias, os cães receberam, como medicação pré-anestésica, atropina 0,02 mg/kg SC (Pasmodex, Isofarma, Brasil) e, 10 minutos após, acepromazina $0,03 \mathrm{mg} / \mathrm{kg} \mathrm{IM}$ (Acepran 0,2\%, Vetnil, Brasil) e morfina 0,8mg/kg IM (Dimorf, Cristália, Brasil) na mesma seringa. A veia safena lateral foi canulada e os membros torácicos foram submetidos à tricotomia. A indução anestésica foi realizada com propofol 3mg/kg IV (Fresofol, Fresenius Kabi, Brasil) e diazepam 0,3mg/kg IV (Diazepam, União Química, Brasil), seguindo-se à intubação endotraqueal e manutenção anestésica por meio da inalação espontânea de isofluorano (Isoforine, Cristália, Brasil) diluído em oxigênio puro, em circuito semifechado de baixo fluxo. $\mathrm{O}$ animal foi então posicionado em decúbito esternal e os membros torácicos foram preparados para cirurgia asséptica com solução degermante à base de iodo e álcool 
iodado. Para controle da dor e inflamação, foram administrados tramadol $3 \mathrm{mg} / \mathrm{kg}$ SC TID (Cloridrato de Tramadol, Teuto, Brasil) e meloxicam 0,2mg/kg IM SID (Maxicam injetável 0,2\%, Ouro Fino, Brasil) durante cinco dias consecutivos, iniciando-se a primeira aplicação imediatamente após o término da cirurgia, bem como antibioticoterapia com cefalexina $(30 \mathrm{mg} / \mathrm{kg}$ VO, BID) durante sete dias consecutivos, iniciando-se a primeira dose no pré-operatório imediato via intravenosa.

Para a exposição óssea, foi realizada uma incisão de pele crânio-medial ao rádio, divulsão do tecido subcutâneo e afastamento lateral da musculatura extensora. $\mathrm{O}$ diâmetro do terço médio do rádio no sentido médio-lateral foi mensurado. Foi então realizada uma ostectomia transversal do terço médio do rádio com extensão correspondente a uma vez e meia o diâmetro do osso. Para realização desse procedimento, foi utilizada uma serra óssea oscilatória pneumática, sob irrigação constante com solução fisiológica. A estabilização óssea foi realizada com uma placa de aço F318 em ponte, posicionada na superfície cranial do rádio e fixada com seis parafusos bicorticais. Após a fixação óssea, o defeito foi tratado de acordo com cada grupo experimental e a síntese tecidual foi realizada de forma rotineira, sendo o tecido subcutâneo aproximado em padrão simples contínuo com fio de poliglecaprone 25 3-0 (Caprofyl, Ethicon, São José dos Campos, Brasil) e a pele em simples separado com náilon nomofilamentar 3-0 (Nylon, Ethicon, São José dos Campos, Brasil).

As avalições radiográficas foram realizadas utilizando-se um aparelho de raio- $x$ digital Regius modelo 110 (Konica Minolta, Tóquio, Japão). Foram realizadas as projeções radiográficas médio-lateral e crânio-caudal de ambos os rádios no pré e pós-operatórios imediatos e aos 15, 30, 45, 60, 75 e 90 dias após a intervenção cirúrgica em cinco animais de cada grupo. Os outros cinco animais de cada grupo foram avaliados radiograficamente até o $45^{\circ}$ dia de pós-operatório, quando foram submetidos à eutanásia para avaliação histológica. A projeção craniocaudal foi utilizada para monitoração do alinhamento ósseo e a projeção médio-lateral, para mensuração das áreas de crescimento ósseo nas linhas de osteotomia. As mensurações foram realizadas com auxílio do software Digimizer
Image Analysis. As áreas correspondentes ao crescimento ósseo foram expressas em percentagem em relação à área total da falha óssea de cada animal considerada $100 \%$.

As avaliações densitométricas e histológicas foram realizadas aos 45 e 90 dias de pósoperatório, sendo utilizados cinco animais de cada grupo em cada um dos períodos de avaliação; utilizando-se apenas os ossos rádios após colheita e fixação em formalina tamponada 10\%. Para isso os animais foram submetidos à eutanásia por meio da aplicação de xilazina $(1 \mathrm{mg} / \mathrm{kg})$ e quetamina $(15 \mathrm{mg} / \mathrm{kg})$, na mesma seringa, via intramuscular, seguida da canulação da veia cefálica e injeção de propofol até parada cardiorrespiratória, seguida da injeção de $40 \mathrm{~mL}$ de cloreto de potássio via intravenosa. Os rádios e ulnas direitos e esquerdos foram dissecados, colhidos e fixados em formalina tamponada $10 \%$ por 30 dias. A avaliação densitométrica foi realizada utilizando-se um densitômetro de dupla emissão de raios-X (Densitômetro DXA, modelo DPX-Alpha Lunar). A densidade mineral óssea $\left(\mathrm{g} / \mathrm{cm}^{2}\right)$ foi mensurada na região correspondente às falhas ósseas com incidência na projeção médio-lateral. Os valores de densidade obtidos de cada falha, de cada animal, foram convertidos em percentagem da densidade óssea normal do rádio de cada animal, considerada $100 \%$. A densidade óssea considerada normal foi obtida na região correspondente aos defeitos tratados com o autoenxerto (controle + ).

Para avaliação histológica e histomorfométrica, os rádios e ulnas foram transversalmente seccionados na altura dos parafusos adjacentes à falha. O segmento ósseo central, contendo a falha, foi submetido ao protocolo de desmineralização com solução aquosa de ácido fórmico $50 \%$ v/v e citrato de sódio $9 \%$ p/v por 90 dias, sendo trocada a cada quatro dias. Após esse período, foi realizada uma secção longitudinal do segmento ósseo correspondente à falha, e as metades foram processadas pela técnica rotineira de inclusão em parafina. Cortes histológicos de $5 \mu \mathrm{m}$ foram obtidos de cada bloco e corados pela técnica da hematoxilina-eosina. As lâminas foram avaliadas descritivamente por microscopia óptica. A área de neoformação óssea foi quantificada com o auxílio de uma ocular micrométrica, contendo uma gratícula com 121 pontos e com objetiva de $4 \times$ percorrendo-se toda a extensão do defeito. A área de neoformação 
óssea foi expressa em relação à área total do defeito de cada animal. Também foi quantificado o número de vasos por campo em 12 campos tomados na área do defeito com objetiva de $20 \times$.

Foi utilizado delineamento inteiramente ao acaso com controle positivo pareado. Os dados foram submetidos à análise de variância (ANOVA) e as médias comparadas pelo teste Student Newman Keuls (SNK), utilizando-se o programa Graphpad Instat 3. Diferenças foram consideradas significativas se $\mathrm{P}<0,05$.

\section{RESULTADOS}

A matriz do BV60S apresentou porosidade média de $97,46 \%$, variando de 97,01 a $97,8 \%$. A microscopia eletrônica mostrou que a matriz apresentava poros interconectados com diâmetro médio de $507 \mu \mathrm{m}$, variando de 300 a $700 \mu \mathrm{m}$ (Fig. $1)$.

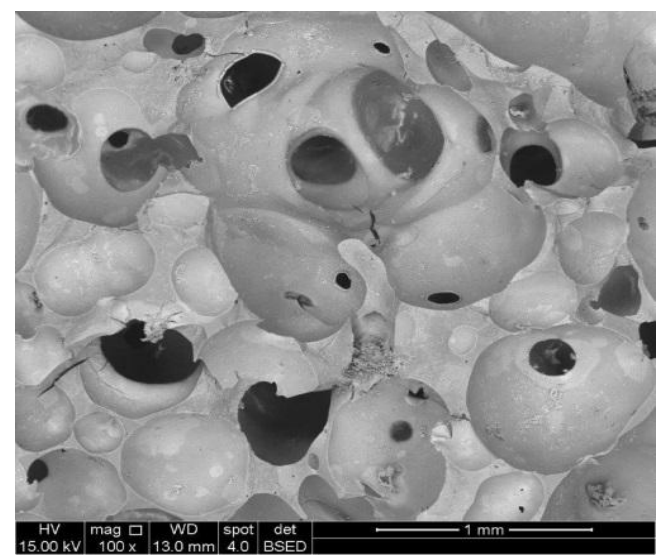

Figura 1. Micrografia de uma amostra da matriz porosa do BV60S obtida por microscopia eletrônica de varredura. Observar a presença de poros interconectados com diâmetro variado. Para as análises das variáveis ilustradas nessa figura foi utilizada estatística descritiva.

A extensão do defeito de uma vez e meia o diâmetro ósseo atingiu o objetivo proposto de criação de defeitos ósseos críticos em rádios de cães. Os controles negativos (C-) mostraram preenchimento ósseo parcial da falha de no máximo $56,68 \%$ sem a formação de ponte óssea entre as extremidades, e os controles positivos $(\mathrm{C}+)$ mostraram regeneração óssea completa em todos os animais aos 90 dias (Fig. 2).

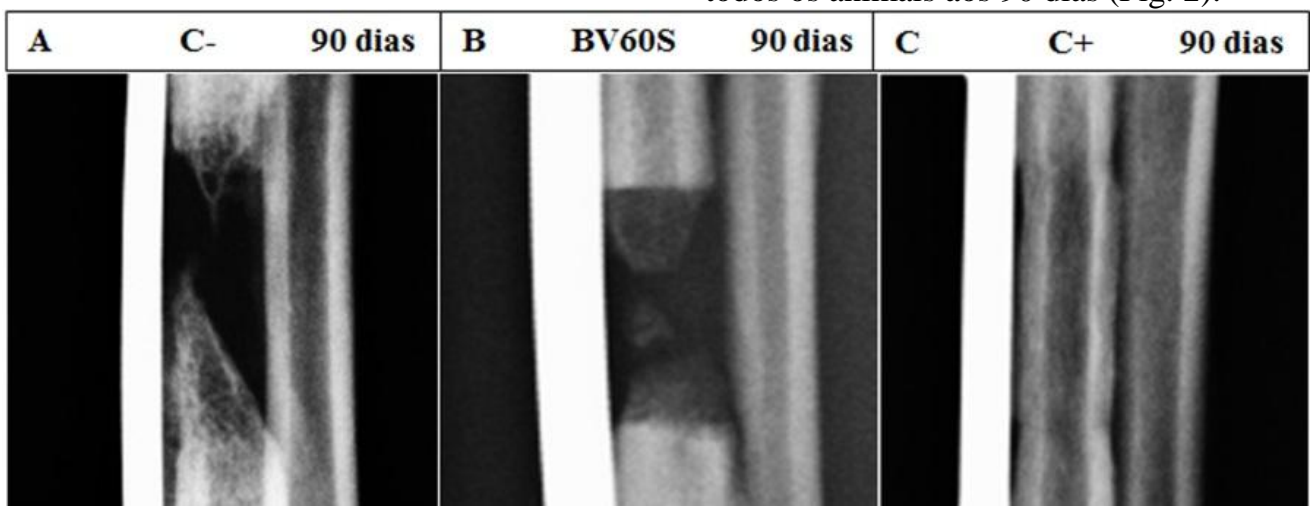

Figura 2. Imagens radiográficas de defeitos ossos críticos em rádios de cães não tratados (A) e tratados com matriz porosa de BV60S (B) e osso autógeno (C), obtidas aos 90 dias de pós-operatório. Observar nas imagens A e B o preenchimento parcial do defeito com osso esponjoso das extremidades em direção ao centro e na imagem. Para as análises das variáveis ilustradas nessa figura, foi utilizada estatística descritiva.

As avaliações radiográficas pós-operatórias permitiram o acompanhamento da regeneração óssea e da evolução de reabsorção da matriz porosa do BV60S durante os 90 dias subsequentes à sua implantação nos defeitos ósseos. A área correspondente ao biomaterial mostrou rápida reabsorção após sua implantação, com redução média de $12,62 \%$ a cada 15 dias (Fig. 3). A matriz porosa do biovidro $60 \mathrm{~S}$ foi completamente reabsorvida em $40 \%$ (dois de cinco) dos animais aos 90 dias. 
A

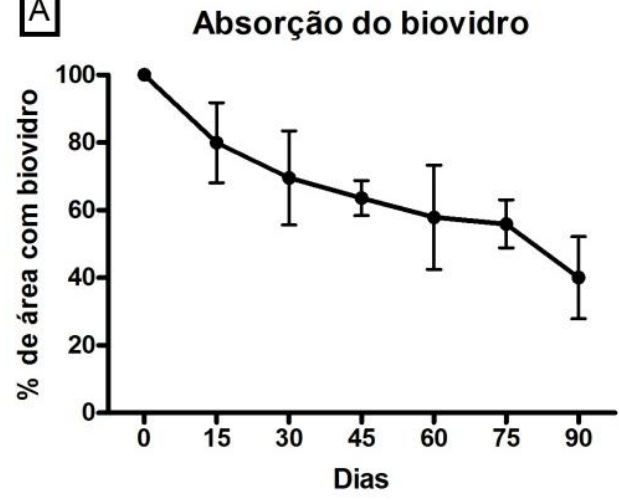

B Biovidro

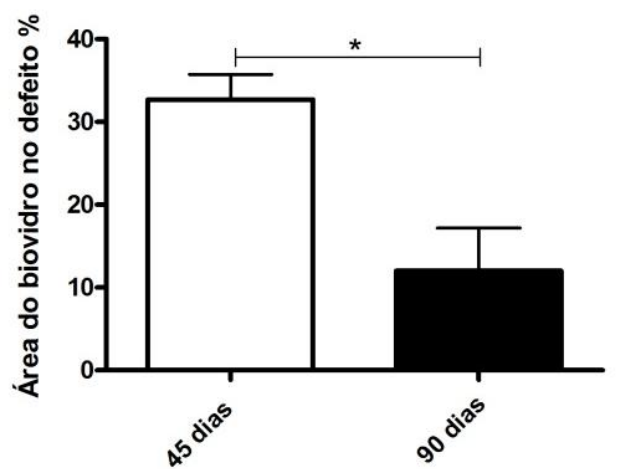

Figura 3. Percentagem média e desvio padrão da área de BV60S em defeitos ósseos críticos em rádios de cães, tratados com matriz porosa de biovidro $60 \mathrm{~S}$, ao longo de 90 dias de avaliação pós-operatória. A medidas obtidas radiograficamente. B - medidas obtidas histologicamente. *Comparação significativa pelo teste de Student Newman Keuls $(\mathrm{P}<0,05)$.

Houve um preenchimento progressivo do defeito, com crescimento ósseo das extremidades em direção ao centro do defeito ósseo até o $75^{\circ}$ dia e uma subsequente redução da área de preenchimento ósseo no período seguinte (90 dias), em todos os grupos estudados (Fig. 4).

Os defeitos tratados com a matriz porosa do BV60S mostraram um crescimento ósseo das extremidades em direção ao centro do defeito ósseo com preenchimento parcial de no máximo
$52,41 \%$, e não houve a formação de ponte óssea entre os fragmentos em nenhum dos animais durante os 90 dias de avaliação (Fig. 2, 4). As áreas de preenchimento ósseo no grupo $\mathrm{BV}$ e $\mathrm{C}$ - foram semelhantes e significativamente inferiores ao controle positivo $(\mathrm{C}+)$ em todos os tempos estudados (Fig. 4). Os controles positivos se regeneram de forma indireta, com a formação de pequenos calos periosteais, medulares e intercorticais, com completa consolidação óssea aos 90 dias em $100 \%$ dos animais.

\section{Área óssea}

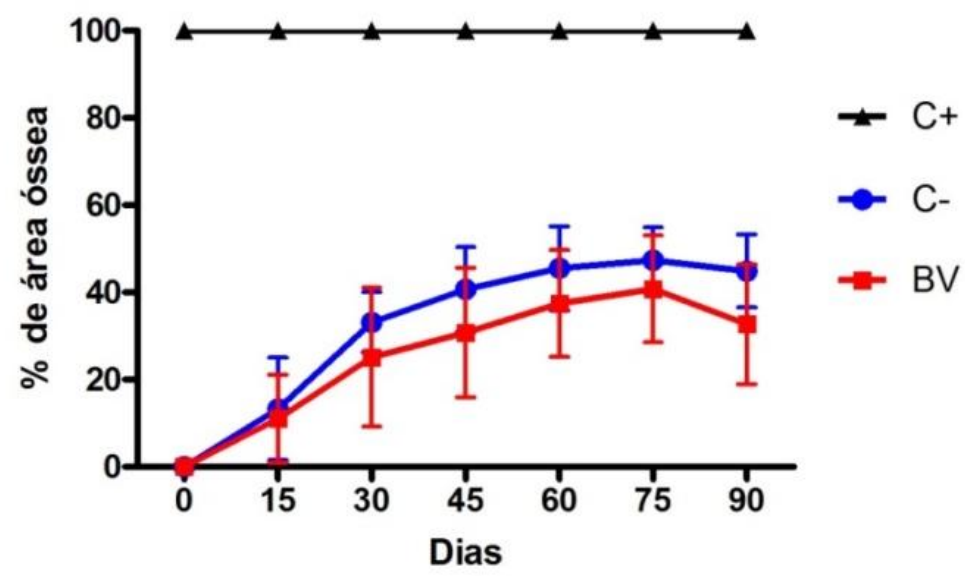

Figura 4. Percentagem média e desvio padrão da área de preenchimento ósseo em defeitos críticos de rádios de cães, não tratados (C-), tratados com matriz porosa de BV60S (BV) e osso autógeno $(\mathrm{C}+)$, ao longo de 90 dias de avaliação pós-operatória (medidas obtidas radiograficamente). Para as análises das variáveis ilustradas nessa figura foi utilizada estatística descritiva.

Os grupos BV e C- apresentaram menor densidade na região do defeito ósseo em relação aos controles positivo $(\mathrm{C}+)$, aos 45 e 90 dias
(Fig. 5). Aos 45 dias, o grupo BV mostrou densidade superior ao grupo controle negativo 
(C-) e, aos 90 dias, nenhuma diferença foi

\section{Densitometria BV60S 45 dias}

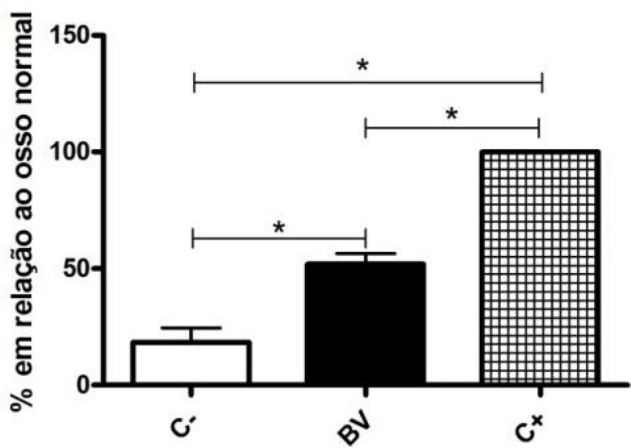

observada entre os grupos C- e BV (Fig. 5).

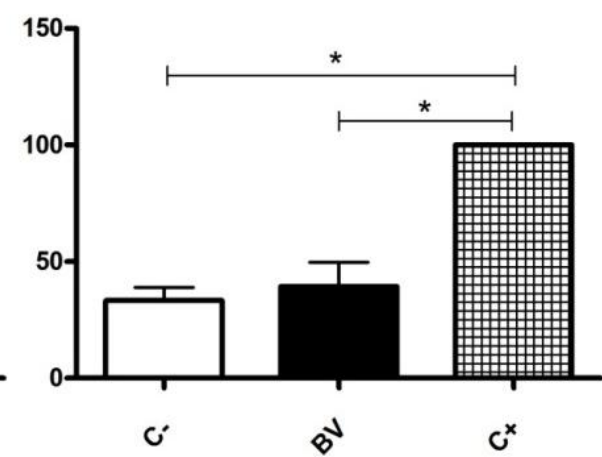

Figura 5. Densidade média e desvio padrão de defeitos ósseos críticos em rádios de cães, não tratados (C-), tratados com matriz porosa de BV60S (BV) e osso autógeno $(\mathrm{C}+$ ), aos 45 e 90 dias de pósoperatório. A densidade está expressa em percentagem relação à densidade normal do rádio de cada animal. *Comparações significativas pelo teste de Student Newman Keuls $(\mathrm{P}<0,05)$.

A avaliação histológica dos grupos controle negativo (C-) e tratado com matriz porosa de BV60S (BV) mostrou neoformação óssea das extremidades do defeito em direção ao centro, sem união entre elas. $\mathrm{O}$ osso neoformado em todos os defeitos dos grupos C- e BV foi esponjoso, com trabéculas espessas (Fig. 6), predominantemente recobertas por osteoblastos volumosos. Verificou-se também uma predominância de osteócitos ativos em lacunas alargadas.

Verificou-se, pela avaliação histomorfométrica, aos 45 e 90 dias, que as áreas de neoformação óssea nos grupos C- e BV foram semelhantes entre si e significativamente inferiores à do controle positivo (Fig. 7).

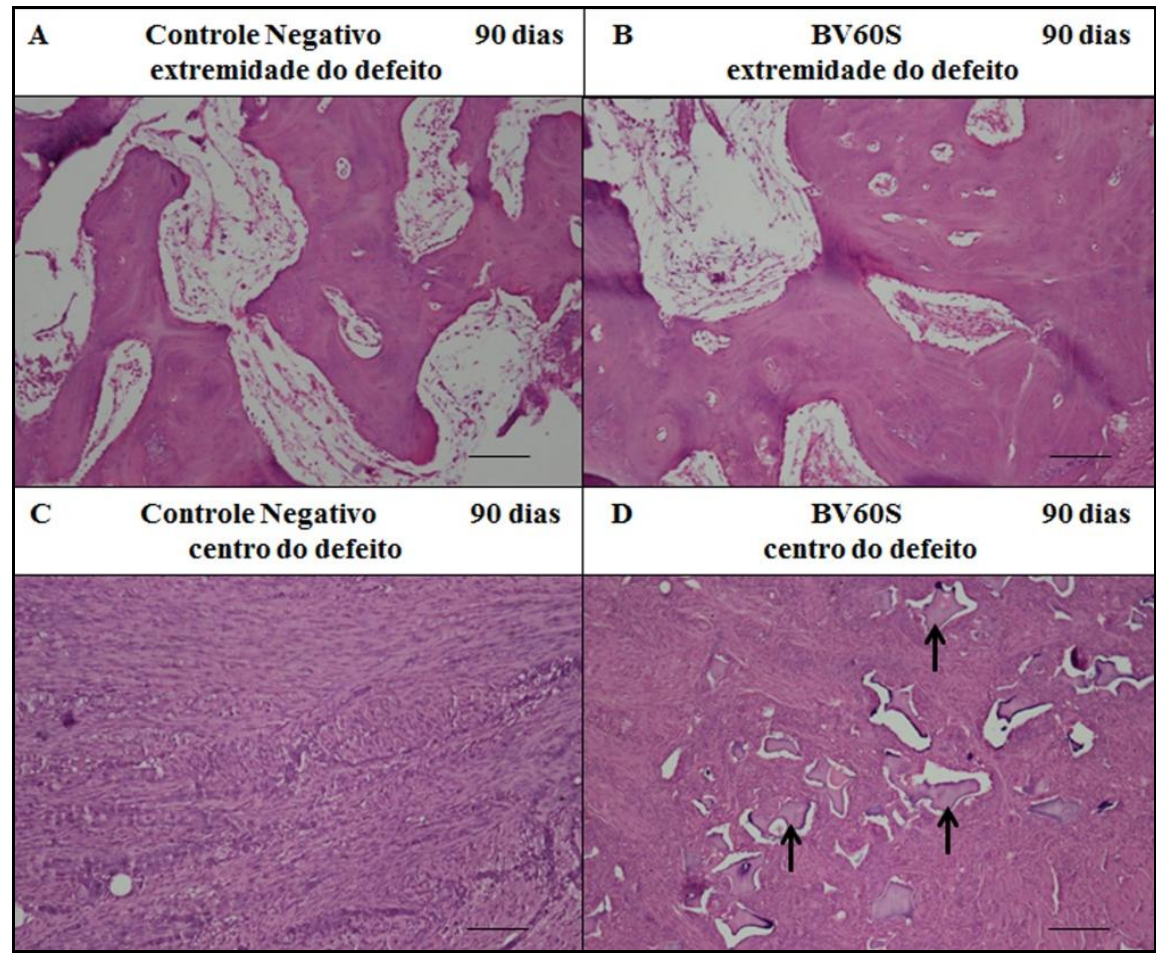


Figura 6. Micrografia do tecido ósseo (A e B) e conjuntivo fibroso (C e D) localizados, respectivamente, na extremidade e no centro de defeitos ósseos críticos em rádios de cães não tratados (A e C) e tratados com matriz porosa de BV60S (B e C) aos 90 dias após a cirurgia. As setas apontam fragmentos do BV60S. Hematoxilina eosina. Barra $=93 \mu \mathrm{m}$.

45 dias

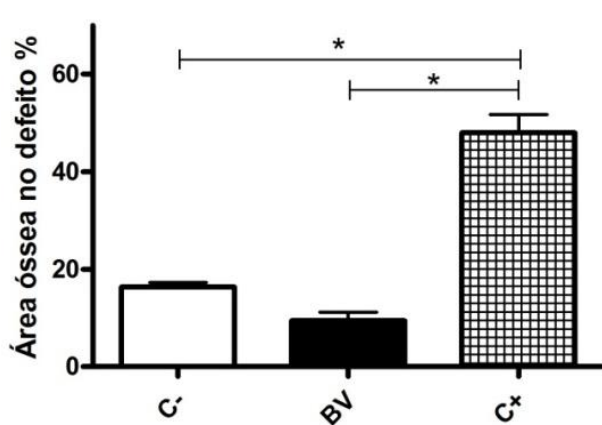

90 dias

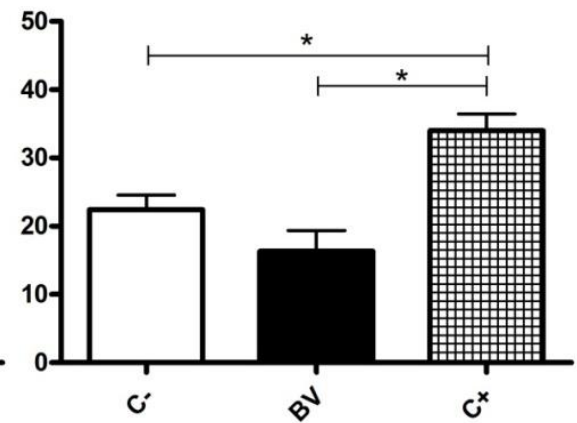

Figura 7. Percentagem média e desvio padrão da área de neoformação óssea em defeitos críticos em rádios de cães, não tratados (C-) e tratados com BV60S (BV) e osso autógeno (C+), aos 45 e 90 dias de avaliação pós-operatória (medidas obtidas por histomorfometria). *Comparações significativas pelo teste de Student Newman Keuls $(\mathrm{P}<0,05)$.

O centro dos defeitos do grupo C- era formado por tecido conjuntivo fibroso desorganizado (Fig. 6) e do grupo (BV) pela matriz do BV60S com tecido conjuntivo no interior dos poros e em torno da matriz (Fig. 6). Observou-se uma significativa redução na quantidade da matriz do BV60S dos 45 para os 90 dias de avaliação (Fig. 3). Aos 90 dias de avaliação, foram observados apenas resquícios na matriz do BV60S, em dois $(40 \%)$ defeitos do grupo BV e raras células gigantes multinucleadas próximas à matriz do BV60S. Não foi observada neoformação óssea no centro dos defeitos em nenhum dos grupos Ce BV. Também não foi observada a presença de infiltrado inflamatório em nenhum dos defeitos de todos os grupos.

Verificou-se predomínio da regeneração óssea endocondral nos defeitos tratados com o osso autógeno (C+), incompleta aos 45 dias e completa aos 90 .

\section{DISCUSSÃO}

O preenchimento parcial dos defeitos ósseos observado aos 90 dias de pós-operatório no grupo controle negativo (C-) (Fig. 2, 4, 6 e 7) comprova que a extensão do defeito ósseo foi suficiente para causar um defeito crítico, que necessita de suporte para regeneração (ASTM 2010). A completa regeneração óssea observada aos 90 dias de pós-operatório em todos os defeitos tratados com o autoenxerto (grupo $\mathrm{C}+$ ) (Fig. 2 e 4) mostra que todos os animais apresentaram capacidade de regeneração óssea normal e que a técnica de estabilização óssea foi adequada.

A maior densidade observada aos 45 dias de pósoperatório no grupo tratado com a matriz porosa do BV60S em relação ao grupo controle negativo (Fig. 5) se deve à maior densidade do biomaterial em relação aos tecidos moles, uma vez que, radiográfica e histologicamente, não foi observada superioridade desse grupo (BV) em relação ao controle negativo quanto à regeneração óssea no defeito (Fig. 2, 4, 6 e 7). Além disso, a semelhança nos resultados da avaliação densitométrica dos grupos C- e BV, aos 90 dias de pós-operatório (Fig. 5), sugere semelhança no processo de regeneração óssea nesses grupos. É valido ressaltar que, nesse período (90 dias), a maior parte da matriz do BV60S já havia sido reabsorvida (Fig. 3 e 6) pelo organismo, reduzindo assim a densidade da área do defeito (Fig. 5). A densitometria óssea é uma técnica que permite avaliação da massa mineral óssea de forma precisa e não invasiva, sendo muito utilizada para diagnóstico e acompanhamento e doenças osteopênicas e na quantificação da massa mineral óssea em estudos de novas terapias para regeneração óssea 
(Almeida Paz e Bruno, 2006). No entanto, quando se estudam biomateriais, como cerâmicas para o tratamento de defeitos ósseos, a avaliação densitométrica não é capaz de diferenciar o aumento de densidade devido à regeneração óssea daquele decorrente do preenchimento da falha com o biomaterial; logo, a interpretação dos resultados deve ser feita com cautela, considerando esse fato.

A regeneração óssea incompleta com preenchimento parcial dos defeitos observada no grupo BV (Fig. 2, 4 e 6) mostra que o BV60S não foi eficiente na regeneração de defeitos ósseos críticos de rádios de cães. Acredita-se que a rápida reabsorção da matriz porosa do BV60S seja a principal causa de insucesso dos tratamentos $\mathrm{BV}$, pois, se a taxa de reabsorção do biomaterial for superior à taxa de neoformação óssea, ocorrerá a formação de uma lacuna entre o osso e o biomaterial, impedindo assim a osteocondução e a completa regeneração do defeito. Essa lacuna entre o biomaterial e o osso é, na maioria das vezes, preenchida por tecido conjuntivo como relatado em estudos semelhantes com outros biomateriais (Liu et al., 2008) e verificado histologicamente neste trabalho. Em um estudo prévio com esse mesmo biomaterial no tratamento de pequenos defeitos em osso alveolar de mandíbulas de cães, o BV60S favoreceu a regeneração óssea sem a formação de tecido conjuntivo na interfase ossoimplante (Dutra et al., 2008). Acredita-se que essa divergência de resultados esteja diretamente relacionada à extensão do defeito, que foi muito superior no presente estudo, e com o tipo e localização do defeito, que, no presente estudo, foi crítico em um segmento completo de osso longo composto principalmente por osso osteônico, que apresenta capacidade regenerativa inferior ao osso trabecular de defeitos alveolares em mandíbulas.

A alta porosidade das matrizes e o baixo grau de organização das moléculas (material amorfo) do BV60S (Fig. 1) são características que lhe conferem alta taxa de reabsorção após sua implantação no organismo. A reabsorção do BV60S leva a liberação de íons $\mathrm{Ca}$ e $\mathrm{Si}$ que favorecer a diferenciação osteogênica de células tronco mesenquimais (Alves et al., 2015), entretanto quando ocorre de forma muito rápida pode ser causa de insucesso. Considerando-se a composição química, os biovidros são os biomaterias que apresentam a maior taxa de reabsorção dentre todas as biocerâmicas (Pereira et al., 2006). O grau de organização das moléculas, também denominado cristalinidade, interfere na taxa de dissolução e reabsorção das biocerâmicas, sendo que, quanto maior a cristalinidade das amostras, menor será sua taxa de reabsorção após implantação no organismo (Hoppe et al., 2011). As características microestruturais da matriz, como porosidade e interconectividade dos poros, também influenciam a taxa de reabsorção. Quanto mais porosa e interconectada a matriz, menor a densidade e maior a área superficial sujeita à ação dos líquidos intersticiais e células, o que ocasiona maior taxa de reabsorção (Rahaman et al., 2011). Além disso, as características do microambiente de implantação, como aporte vascular, aumento de $\mathrm{pH}$, presença de edema e aumento de temperatura local, podem acelerar a reabsorção das cerâmicas (Chai et al., 2012).

Por outro lado, a alta porosidade $(97 \%)$ e o

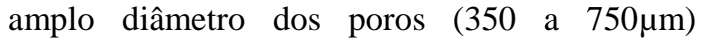
interconectados observados nas matrizes dos biovidro 60S facilitam sua colonização e neovascularização, como observado histologicamente. O tamanho dos poros da cerâmica deve ser semelhante ao do osso esponjoso para permitir a invasão vascular, colonização celular e substituição por tecido ósseo (Geissler, 2006). Chen et al., (2001)

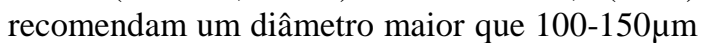
e Geissler (2006) cita que o diâmetro dos poros deve variar entre 150 e $500 \mu \mathrm{m}$, mas salienta que poros muito amplos podem enfraquecer a matriz. De Long Jr. et al (2007) relatam que o tamanho ideal dos poros deve ser de 300 a $500 \mu \mathrm{m}$, pois permite maior colonização do implante. Tão importante quanto o diâmetro dos poros é a presença de interconectividade entre eles (Chen et al., 2001; Geissler, 2006; De Long Jr. et al., 2007), pois isso influencia diretamente na tensão de oxigênio, fator de importância relevante na diferenciação das células-tronco mesenquimais em células osteoprogenitoras e destas em osteoblastos (Chung et al., 2012). Ao estudar a colonização e diferenciação de células-tronco mesenquimais em matrizes de hidroxiapatita, Mygind et al. (2007) observaram maior colonização nas amostras com poro de diâmetro médio de $500 \mu \mathrm{m}$ e maior diferenciação celular nas amostras com diâmetro de $200 \mu \mathrm{m}$. 
Uma alternativa para melhorar o desempenho da matriz porosa do BV60S é associá-la com células osteoprogenitoras capazes de sintetizar de matriz óssea e favorecer a regeneração de grandes defeitos ósseos (Chai et al., 2012; Alves, 2013); entretanto, outros estudos devem ser realizados para comprovar essa hipótese.

\section{CONCLUSÃO}

Nas condições em que foi realizado este estudo, pode-se afirmar que: a matriz porosa do biovidro 60S não é eficiente no tratamento de defeitos ósseos críticos no rádio de cães adultos.

\section{AGRADECIMENTOS}

Os autores agradecem à FAPEMIG pelo financiamento do projeto de pesquisa, ao $\mathrm{CNPq}$ pela bolsa de estudo de doutorado, à Escola de Veterinária, ao Laboratório de Biologia Molecular do Departamento de Imunologia e Bioquímica do Instituto de Ciências Biológicas da UFMG e ao Laboratório de Densitometria da Faculdade de Medicina Veterinária da Universidade Estadual Paulista "Júlio de Mesquita Filho" pelo suporte necessário para completar o presente estudo.

\section{REFERÊNCIAS}

ALMEIDA PAZ, I.C.L.; BRUNO, L.D.G. Bone mineral density: review. Rev. Bras. Cienc. Avic., v.8, p.69-73, 2006

ALVES, E.G.L. Células tronco mesenquimais de cães associadas ou não à vidro bioativo, Diferenciação osteogenica in vitro e tratamento de defeitos ósseos críticos. 2013. 108f. Tese (Doutorado em Ciência Animal) - Escola de Veterinária, Universidade Federal de Minas Gerai, Belo Horizonte, MG.

ALVES, E.G.L.; SERAKIDES, R.; ROSADO, I.R. et al. Efeito do produto iônico do biovidro $60 \mathrm{~S}$ na diferenciação osteogênica de células tronco mesenquimais do tecido adiposo de cães. Arq. Bras. Med. Vet.,v.67, p.969-978, 2015.

CHAI, Y.C.; CARLIER, A.; BOLANDER, J. et al. Current views on calcium phosphate osteogenicity and the translation into effective bone regeneration strategies. Acta Biomater., v.8, p.3876-3887, 2012.

CHEN, G.; USHIDA, T.; TATEISHI, T. Development of biodegradable porous scaffolds for tissue engineering. Mater Sci. Eng. C. v.17, p.63-69, 2001.
CHUNG, D.; HAYASHI, K.; TOUPADAKIS, C.A. et $a l$. Osteogenic proliferation and differentiation of canine bone marrow and adipose tissue derived mesenchymal stromal cells and the influence of hypoxia. Res. Vet. Sci. v.91, p.66-75, 2012.

COELHO, M. B.; PEREIRA, M. M. Sol-gel synthesis of bioactive glass scaffolds for tissue engineering: effect of surfactant type and concentration. J. Biomed. Mater Res. B Appl. Biomater., v.75, p.451-456, 2005.

DE LONG JR, W.G.; EINHORN, T.A.; KOVAL, K. et al. Bone grafts and bone substitutes in orthopaedic trauma surgery. A critical analysis. J Bone Joint Surg., v.89, p.649-658, 2007.

DUTRA, C.E.; PEREIRA, M.M.; SERAKIDES, R. et al. In vivo evaluation of bioactive glass foams associated with platelet-rich plasma in bone defects. $J$. Tissue Eng. Regen. Med. v.4, p.221-227, 2008.

GEISSLER, W.B. Bone graft substitutes in the upper extremity. Hand Clin., v.22, p.329-339, 2006.

HENCH, L.L. Genetic design of bioactive glass. $J$. Eur. Ceram. Soc., v.29, p.1257-p.1265, 2009.

HOPPE, A.; GÜLDAL, N.S.; BOCCACCINI, A.R. A review of the biological response to ionic products from bioactive glasses and glass-ceramics. Biomaterials, v.32, p.2757-2774, 2011.

LIU, G.; ZHAO, L.; ZHANG, W. et al. Repair of goat tibial defects with bone marrow stromal cells and $\beta$ tricalcium phosphate. J. Mater Sci.: Mater Med., v.19, p.2367-2376, 2008 .

MYGIND, T.; STIEHLER, M.; BAATRUP, A. et al. Mesenchymal stem cell ingrowth and differentiation on coralline hydroxyapatite scaffolds. Biomaterials. v.28, p.1036-1047, 2007

PEREIRA, M.M.; VASCONCELOS, W.L.; ZAVAGLIA, C.A.C. Materiais cerâmicos - Ciência e aplicações como biomateriais. In: ORÉFICE, R.L.;

PEREIRA, M.M.; MANSUR, H.S. (Ed) Biomateriais fundamentos $e$ aplicações. Rio de Janeiro: Cultura Médica. 2006. p.39- 58.

PIERMATTEI, D.L.; FLO, G.L.; DECAMP, C.E. Handbook of small animal orthopedics and fracture repair. 4.ed. St. Louis: Saunders, 2006. 832p.

RAHAMAN, M.N.; DAY, D.E.; BAL, S. et al. Bioactive glass in tissue engineering. Acta Biomater.,v.7, p.2355-2373, 2011.

STANDARD guide for pre-clinical in vivo evaluation in critical size segmental bone defects. Active Standard ASTM F2721-09. [s.1.]: ASTM International, 2010. (Book of Standards, v.13.02).

VALÉRIO, P.; PEREIRA, M.M.; GOES, A.M. et al. The effect of ionic products from bioactive glass 
Matriz porosa...

dissolution on osteoblast proliferation and collagen production. Biomaterials, v.25, p.2941-2948, 2004. 